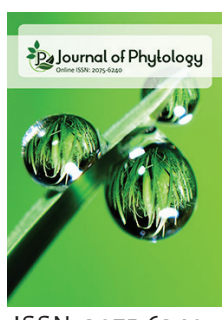

ISSN: $2075-6240$

Received: November 24, 2019 Accepted: March 26, 2020 Published: April 09, 2020

*Corresponding Author: Chiranjeevi Muppala Email: muppala.chiranjeevi2016@ vitstudent.ac.in

\title{
Machine vision detection of pests, diseases and weeds: A review
}

\author{
Chiranjeevi Muppala*, Velmathi Guruviah \\ Department of Electronics and Communication Engineering, VIT Chennai - 600127, Tamil Nadu, India
}

\begin{abstract}
Most of mankind's living and workspace have been or going to be blended with smart technologies like the Internet of Things. The industrial domain has embraced automation technology, but agriculture automation is still in its infancy since the espousal has high investment costs and little commercialization of innovative technologies due to reliability issues. Machine vision is a potential technique for surveillance of crop health which can pinpoint the geolocation of crop stress in the field. Early statistics on crop health can hasten prevention strategies such as pesticide, fungicide applications to reduce the pollution impact on water, soil, and air ecosystems. This paper condenses the proposed machine vision relate research literature in agriculture to date to explore various pests, diseases, and weeds detection mechanisms.
\end{abstract}

KEYWORDS: Machine vision, Pest detection, Disease detection, Weed detection, Multispectral, Hyperspectral

\section{INTRODUCTION}

Agriculture plays an important role in procuring food security, soothe poverty and bolster development. The world's population is expected to reach 9.7 billion in 2050 and 11.2 billion by the end of this century [1], so food production must increase despite various crop yield affecting factors like pests, weeds, pathogens, nutrients, water, sunlight, soil degradation, environmental impacts, and sparse arable land. The manual crop inspection is slow, error-prone due to human mistakes and parts of the field may be hard to reach results in poor efficiency. Technology adaptation is very crucial for more efficient food production.

The machine vision systems (MVS) can automate crop inspection with the help of in-situ and ex-situ imaging techniques to improve overall crop yield. Compared to human vision, they can predict the problems in the crop more precisely by analyzing information acquired from the images. The biotic factors damage severity varies with type and variant of the crop, geolocation, and weather conditions. Yield losses of wheat, maize, cotton and rice crops due to biotic factors (pests, diseases, and weeds) in 2001-03 [2] are depicted in Figure 1. Over the year's biotic factors are becoming more and more immune to pesticides, herbicides, and fungicides causing more damage to the crop yield. This review paper concentrates on various machine vision techniques proposed for identifying pests, diseases, and weeds in the agriculture field. MVS has great potential in identifying natural resources, precision farming, product quality assessment, sorting, classification and so forth. They can recognize the color, shape, size, and texture of an object and can find the point of interest from them. MVS can capture invisible lights such as ultraviolet, IR, and NIR, which render better information regarding crop health [3].

\section{MATERIALS AND METHODS}

\section{A. Pest Detection using Machine Vision}

RGB images of the traps can be processed to detect and recognize pests when pest traps and lures are placed in the field. Multispectral and hyperspectral imaging systems[4] use the texture and color of the crops for problem identification. Different spectral bands provide distinctive information regarding the plants, for instance, visible spectrum (VIS) renders leaf pigmentation information and the plant's physiological condition can be collected from NIR bands [5].

Singh et al. [6]investigated the damaged wheat kernels using LWIR hyperspectral imaging. Rice weevils, lesser grain borer, red flour beetles, and rusty grain beetles affected wheat kernels scanned in the wavelength of 1-1.6mm. InGaAs camera (Model no. SU640-1.7RT-D, Sensors Unlimited Inc.,) along with two 300W halogen-tungsten lamps as illumination sources used for detection. Captured hyperspectral data was fed to a digital data acquisition board (Model no. NI PCI-1422, National Instruments Corp). The data then converted to greyscale intensity images from matrix format. 48 different features extracted from the image and utilized in the classification.

Copyright: $\odot$ The authors. This article is open access and licensed under the terms of the Creative Commons Attribution License (http://creativecommons.org/licenses/by/4.0/) which permits unrestricted, use, distribution and reproduction in any medium, or format for any purpose, even commercially provided the work is properly cited. Attribution - You must give appropriate credit, provide a link to the license, and indicate if changes were made. 


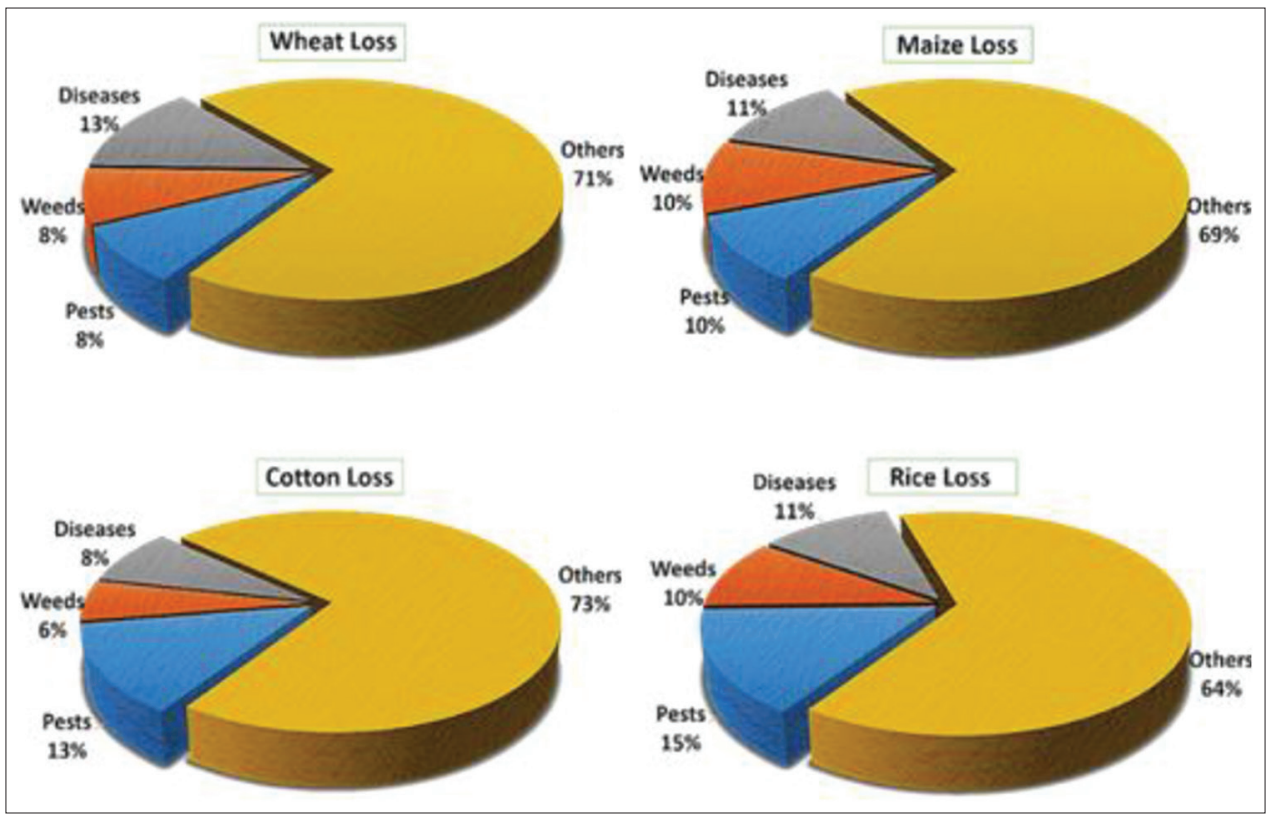

Figure 1: Yield loss share of pests, diseases, and weeds in wheat, maize, cotton, and rice crops [2]

Linear discriminant analysis (LDA) and quadratic discriminant analysis (QDA) classifiers were used, healthy and pest infected kernels uniquely classified with an accuracy of $85-100 \%$. Working in the Long-wave NIR region is very costly due to the high-cost InGaAs detector. So in their succeeding work [7] attempted to lower system cost without compromising the performance by replacing long-wave NIR detectors with lowcost shortwave NIR charge-coupled device (CCD) detectors. They used a CCD area scan image sensor (Model no. C7042, Hamamatsu Photonics) working in the NIR and VIS regions. For comparison, a 2MP color imaging camera was used along with the detector and achieved an accuracy of 92.7-100\%.

Yao et al. [8] described a rice pest's identification system by using two 12MP Nikon digital cameras placed on top and bottom of a glass plate with 4 black light sources to lure pests. The main aim was to detect four different rice pests from lepidoptera species, sesamia inferens, pararaguttata bremeret, cnaphalocrocis medinalis, and chilo suppressalis. They achieved an average accuracy of $90.5 \%$ without cross-validation and $97.5 \%$ by 7 fold cross-validation. The major challenge is insect overlapping, in such cases, manual separation is performed. In their succeeding work [9], they tried to automate the separation of overlapped insects by tapping the glass plate lightly and capturing the image after that. Asefpour and Vakilian [10]developed a system to identify beet armyworm (spodoptera exigua), a serious pest of vegetable, field, and flower crops. Armyworms acquired from a sugar beet farm and placed in a dark chamber for image acquisition. The images captured with a Canon CCD digital camera along with an LDR lightening module. An array of 200 LED's used for light focus on the surface plate for uniform light reflections of the worm. 100 armyworm images and 100 other pest species images collected. From each image, four morphological (area, perimeter, eccentricity, and sphericity) and three textural features (local homogeneity, entropy, and energy) were extracted and prepared a dataset. 150 images utilized for training ANN classifier and remaining for evaluation. ANN classifier was able to classify armyworms with an accuracy of $90 \%$.

Qing et al. [11]proposed a technique to gauge white-backed planthopper (WBPH) population density in the paddy field. A smartphone and a Wi-Fi enabled 14MP digital camera (Samsung SH100) were used. The digital camera attached to a stretchable pole and remotely controlled by a smartphone to capture WBPH on rice stems. Counting was done in three-layer detection mechanism, the first layer is an AdaBoost classifier, the second is a support vector machine (SVM) classifier based on the histogram of oriented gradient (HOG), and the third layer used threshold judgment based on one color and three shape features of the WBPH. They achieved a detection accuracy of 90.7\% with 4.9\% false detection rate. Prasannakumar et al. [12] has studied reflectance of brown planthopper (BPH) attacked rice crop by capturing reflectance of the crop with various wavelengths from $350-2500 \mathrm{~nm}$ i.e. VIS $(400-700 \mathrm{~nm})$, NIR (740-925nm), and MIR (1450-1975nm) regions. A fieldspec3 spectroradiometer (analytical spectral devices, Boulder, USA) was used and kept at a height of $0.8 \mathrm{~m}$ above the crop at an angle of $25^{\circ}$ field of view to cover the entire rice canopy. Collected images in various wavelengths analyzed using one-way analysis of variance (ANOVA). By comparing level 0 to level 9, they proved that the NIR band is well suited for the detection of BPH damage in the rice field.

Ding and Taylor [13] developed a system for monitoring the number of insects on a pest trap with pheromones. Moths are being uniquely identified and the number of moths trapped counted in real-time. For identification, they proposed a sliding window-based detection pipeline, where captured image patches from around the image analyzed by the convolutional neural network (CNN) to ascertain the possibility of moth's presence. Thresholding was applied on the filtered image patches according to their associated confidences and location 
for confirmation. They have achieved an accuracy of $93.1 \%$ with 0.099 log-average miss rate with trap liners rarely changed and achieved $93.4 \%$ accuracy with a log-average miss rate of 0.091 with trap liners changed regularly. Rajan et al. [14] proposed an automatic pest identification system to detect whiteflies, aphids, and cabbage moths. Digital camera (VIS) was used to capture images of the crop which may have pests on their leaves. Images of different pests collected, then their histograms were determined and kept in a database. SVM classifier trained with threshold values and the slack variables of the images in the database. The threshold value was used to distinguish the object from the background and classification of the pests was done using slack variables. They achieved a detection accuracy of $95 \%$.

Doitsidis et al. [15]implemented a web-based pest detection system to detect and count olive fruit flies (bactrocera oleae) in olive orchards. They used an automatic McPhail trap with a 2MP digital camera and embedded hardware powered by a $7000 \mathrm{mAh}$, $12 \mathrm{~V}$ battery. The glass trap was filled with $200 \mathrm{ml}$ of ammonium sulfate which attracts olive fruit flies. The images of trapped fruit flies were captured and sent to a web server through TELIT (model: GM862) GSM module. When a new image uploaded to the server, a pre-programmed listener module activates the image analyzer and system monitoring components. One-way ANOVA used to analyze the image online. Black areas (black pixels) in the images indicate fruit flies and their dimensions with respect to the area of interest given the total number of trapped flies. They achieved a detection accuracy of $75 \%$.

Ebrahimi et al. [16] developed an imaging system in the strawberry greenhouse to detect thrips and classify parasites.
They used an 18MP Canon EOS M digital camera on a LabVIEW program-controlled horizontal mobile agricultural robot, to capture the strawberry flower images. With color indexing and SVM classification, they were successful in identifying thrips with an accuracy of greater than $97.5 \%$. Sun et al. [17] proposed a deep learning method for counting adult red turpentine beetles in the pine trees using a pheromone trap. They used a deep learning detector (RTBnet) running on embedded devices. The runtime tests were performed on Arm platforms with GPU acceleration (NVidia Jetson TX2) and raspberry pi3 platform without GPU acceleration. They got object-level average precision of 0.746. [18] developed an automatic Asian citrus psyllid pests detection and counting system in the citrus crop. The system has 6 cameras to capture images of psyllid pests falling on a board fixed to a mobile vehicle which has a tapping unit to shake citrus tree branches. NVIDIA TX2 embedded computational unit with convolutional neuralnetworks used to identify psyllids from captured images. They achieved precision and recall of $80 \%$ and $95 \%$, respectively. An overview of different MVS pest detection methods was shown in Table.1.

\section{B. Disease Detection Using Machine Vision}

Crop diseases are classified based on plant's visual symptoms, infected plant organs, the type of plants, and pathogens as shown in Figure 2. The disease may be an infectious disease (fungi, bacteria, viruses, etc.) or a non-infectious disease (due to nutrient deficiencies, soil acidity, mineral toxicities and the like) [19]. Franke and Menz [20] developed a system to monitor fungal diseases of wheat using multispectral satellite images.

Table 1: Machine vision systems for pest detection

\begin{tabular}{|c|c|c|c|c|c|c|}
\hline Type of Crop & Name of the Pest & Type of Sensor & Spectral bands & Main tool & Accuracy & References \\
\hline Wheat & $\begin{array}{l}\text { Rice weevils, } \\
\text { Lesser grain borer, } \\
\text { Red flour beetles, } \\
\text { Rusty grain beetles. }\end{array}$ & $\begin{array}{l}\text { InGaAs Camera } \\
\text { (M.no. SU640-1.7RT-D, Sensors } \\
\text { Unlimited Inc.) }\end{array}$ & LWIR & QDA, LDA Classifiers & $>85 \%$ & [6] \\
\hline Wheat & $\begin{array}{l}\text { Rice weevils, } \\
\text { Lesser grain borer, } \\
\text { Red flour beetles, } \\
\text { Rusty grain beetles. }\end{array}$ & $\begin{array}{l}\text { CCD area scan image sensor (M.no. } \\
\text { C7042, Hamamatsu Photonics), } \\
\text { Digital Camera }\end{array}$ & VIS, SWIR & QDA, LDA Classifiers & $>92.7 \%$ & {$[7]$} \\
\hline Paddy & $\begin{array}{l}\text { Chilo suppressalis, } \\
\text { Sesamia inferens, } \\
\text { Cnaphalocrocis medinalis, } \\
\text { Pararaguttata bremeret. }\end{array}$ & $\begin{array}{l}\text { Digital Camera } \\
\text { (12MP, Nikon) }\end{array}$ & VIS & SVM & $97.5 \%$ & [8] \\
\hline Multiple Crops & Beet armyworm & $\begin{array}{l}\text { Digital Camera (Canon, Power } \\
\text { shot, G12) }\end{array}$ & VIS & ANN & $90 \%$ & {$[10]$} \\
\hline Paddy & WBPH & Digital Camera & VIS & $\begin{array}{l}\text { AdaBoost \& } \\
\text { SVM Classifiers }\end{array}$ & $85.2 \%$ & {$[11]$} \\
\hline Paddy & $\begin{array}{l}\text { Brown plant hopper } \\
\text { (BPH) }\end{array}$ & $\begin{array}{l}\text { Spectroradiometer } \\
\text { (ASD, Boulder) }\end{array}$ & VIS, NIR, MIR & One-way ANOVA & - & [12] \\
\hline Multiple Crops & Codling moth & Digital Camera & VIS & ConvNets (CNN) & $93.4 \%$ & [13] \\
\hline Multiple Crops & $\begin{array}{l}\text { Whiteflies, } \\
\text { Aphids, } \\
\text { Cabbage moths. }\end{array}$ & Digital Camera & VIS & SVM & $95 \%$ & [14] \\
\hline Olive Orchids & Olive fruit flies & Digital Camera (2MP) & VIS & One-way ANOVA & $75 \%$ & [15] \\
\hline Strawberry & Thrips & $\begin{array}{l}\text { Digital Camera } \\
\text { (Canon EOS M, 18MP, CMOS) }\end{array}$ & VIS & SVM & $>97.5 \%$ & [16] \\
\hline Pine trees & Red turpentine beetles & Digital Camera & VIS & RTBnet & $74.6 \%$ & [17] \\
\hline Citrus & $\begin{array}{l}\text { Asian citrus } \\
\text { psyllid }\end{array}$ & Digital Camera & VIS & CNN & $80 \%$ & [18] \\
\hline
\end{tabular}




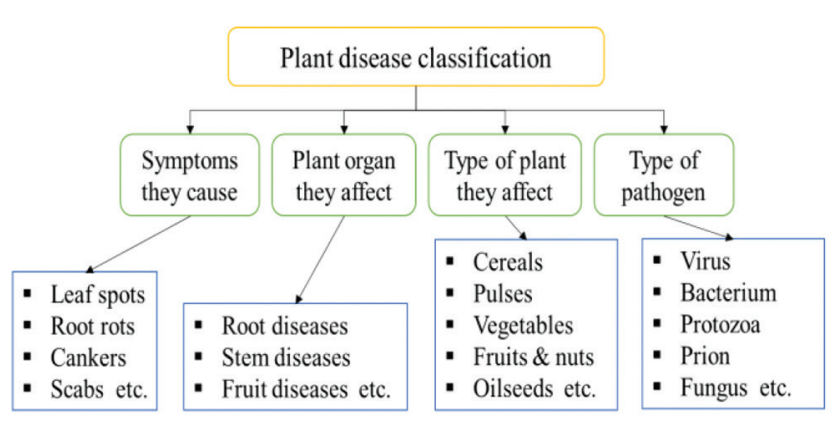

Figure 2: Plant disease classification

The focus is on powdery mildew (Blumeria graminis), and leaf rust (Puccinia recondita), the two most common pathogens in cereals of central Europe. The target field plot divided into 3 sub-areas and applied with different dosages of fungicide for a variety of infection severity analysis. QuickBird satellite data of the target area was acquired in the year 2005 on $22^{\text {nd }}$ April when the infection is at the earliest and on $20^{\text {th }}$ June. On $28^{\text {th }}$ May airborne hyperspectral HyMap sensor's (450-2480nm, 126 bands, and $4 \mathrm{~m}$ spatial resolution) data also collected. A spectral library was created with the data acquired from each date. Apart from QuickBird and HyMap sensor data, the ground truth data also often collected in the field at 54 sample points for cross-validation. A decision tree was built using spectral mixture analyses (SMA), normalized difference vegetation index (NDVI) and deviation of the NDVI used for detecting infected areas. With SMA classifier they achieved an overall accuracy of $56.8 \%, 65.9 \%, 88.6 \%$ for data collected on respective dates. Phadikar and Sil. [21]implemented a method to detect leaf blast and brown spot diseases in the paddy field. Diseased leaves collected from various parts of Midnapore and their images captured using a digital camera (Nikon COOLPIX P4). After adjusting the contrast and brightness of the images they were transformed into a hue intensity saturation (HIS) model, then segmented using entropy-based bi-level thresholding method. Self-organizing map (SOM) neural network used for disease categorization. The classifier was trained with 300 different patterns and 50 epochs, achieved detection accuracy of $92 \%$.

Bauer et al. [22] investigated the automatic classification of leaf diseases, Cercospora beticola (leaf spot pathogen cercospora), Uromyces betae (rust fungus) in sugar beet plants. Healthy and disease infected plant leaves collected and placed in a light illumination controlled environment for image acquisition. From four different positions, four RGB images (FujiFilm FinePix S5600), and one multispectral image (Tetracam ADC) of each leaf was captured to prepare a 3D model by image fusion. RGB camera position and rotation controlled by AURELO program [23] and the 3D structure of leaves were prepared using INPHO-Software MATCH-T [24]. The 3D model of the leaves classified using pixel-wise K-nearest neighbor (KNN), pixel-wise adaptive Bayes classification using Gaussian mixture model and a conditional random fields (CRF) classifier. Achieved median of pixel-wise classification accuracy of $86 \%$ in the detection of uromyces betae, $91 \%$ for cercospora beticola and healthy leaf areas were detection with an accuracy of $94 \%$.
Santoso et al. [25] studied a method to map and detect Ganoderma boninense pathogen affected basal stem rot disease in oil palm. Visible, NIR and panchromatic (450-900 nm) spectral bands of Quick bird images were used for the study. ArcGIS 9.2 and ENVI 4.3 image processing systems used to identify the disease infestation from the satellite data. Identification and mapping of infection done in two stages, in the first stage image segmentation performed to delineate dead palm trees due to the stem rot infection, diseased living palm trees identified in the second stage using six different vegetation indices (ARVI, GNDVI, GBNDVI, NDVI, SAVI, and SR). Four different palm fields (aged 21 (field-I), 16 (field-II), 15 \& 18 (field-III), and 10 (field-IV) years) were chosen and then six vegetation indices applied on the captured images for disease identification. Manual field samples collected for comparison with the images interpreted from quick bird imagery. In the field-I GBNDVI and ARVI were the most accurate with disease interpretation accuracy of $85 \%$, SR vegetation indices achieved an accuracy of $85 \%$ in field-II, 73\% of maximum accuracy was achieved by GBNDVI in field-III and in field-IV, GBNDVI, and GNDVI gave $84 \%$ accuracy.

In 2012, Wang et al. [26] developed an approach to detect diseases in grape (grape downy mildew \& grape powdery mildew) and wheat crops (wheat stripe rust \& wheat leaf rust). A total of 185 digital images collected and then segmented with K-means clustering algorithm. From segmented images twenty-one color features, twenty-five texture features, and four shape features were extracted. Back Propagation (BP) networks used as the classifier for disease identification. Some of the images randomly chosen to train the classifier and remaining used as the test set. The author achieved an accuracy of $100 \%$ in detecting both the crop diseases with BP networks.

Phadikar et al. [27] proposed a method to detect four different diseases, bacterial blight, leaf brown spot, rice blast, and sheath rot in rice crop, and the infected leaves are shown in Figure 3. The color, position, and shape of the infected regions were used for disease classification. The diseased leaf visual symptoms were extracted using Fermi energy-based region extraction method, then the genetic algorithm applied in two steps to detect the shape (diamond, rectangular, circular, oval, elliptical, or irregular) of the infected region. The infected region's position detected by partitioning the image into blocks, then arranged into different groups with labels. The rule generation algorithm used as a classifier to classify the collected disease infected image datasets and the results were compared with existing classifiers using 10 -fold cross-validation and obtained an average accuracy of $94.21 \%$.

Liaghat et al. [28]used Fourier transform infrared (FT-IR) spectroscopic technique to identify and discriminate different stages of oil palm's basal stem rot disease infestation. FTIR spectrometer (Thermo Fisher Scientific Inc., USA) has a spectral range of $2.55-25.05 \mu \mathrm{m}$ with 451 spectral bands. Four different classification algorithms used to classify data captured by spectrometer namely KNN, Linear discriminant analysis (LDA), Naive-Bayes (NB), and QDA. QDA and LDA algorithms have given a high average overall classification accuracy of over $85 \%$. With pre-processed FT-IR spectral data 


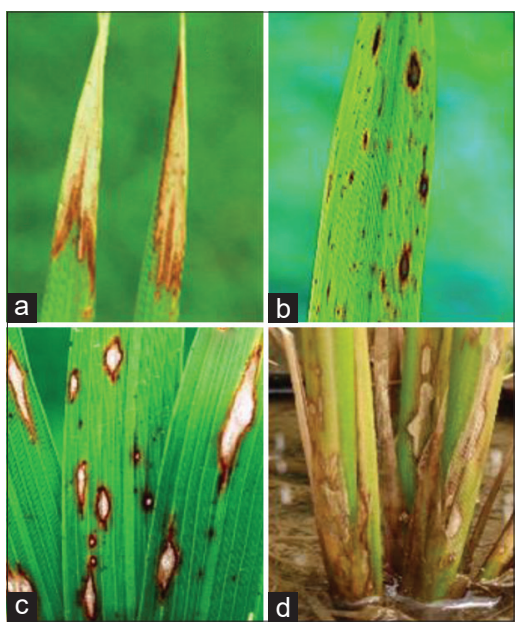

Figure 3: Rice leaves infected by a) Bacterial blight b) Leaf brown spot c) Rice blast d) Sheath rot

LDA was able to differentiate between healthy and infected leaf samples with high classification accuracies $(>90 \%)$. Pourreza et al. [29] proposed a system to detect citrus greening (Huanglongbing (HLB)) bacterial infection in citrus trees. They used a monochrome camera (DMK23G445, the imaging source, Germany) with a CCD sensor, ten LEDs with high luminous efficiency for illumination. 60 citrus leaves collected from citrus trees used as test samples, some healthy and some with HLB infection. The SVM classifier was trained with the mean and standard deviation for disease detection. They achieved a maximum detection accuracy of $98.5 \%$.

Schor et al. [30] developed a robotic disease detection system to identify two serious diseases, tomato spotted wilt virus (TSWV) \& powdery mildew (PM) in bell peppers greenhouse. The system has 3 major parts, a robotic manipulator (MH5L, Motoman, Japan), custom made end-effector and a sensory apparatus comprising a VIS camera and a laser sensor (DT35, SICK). The PCA-based algorithm and two variants of coefficients of variation (CV) algorithms used for disease identification. PM detection accuracy of $90 \%$ achieved using PCA-based algorithm and two variants of CV algorithms achieved 84\%, 87\% accuracies in detecting TSWV disease. [31] proposed a method for early detection of gray mold disease caused by Botrytis cinerea fungus in tomato crops using hyperspectral imaging. The setup has a digital CCD camera (M C8484-05, Hamamatsu City), an imaging spectrograph (V10E, Specim, Oulu), and two halogen light sources.

They collected 42 healthy and 170 gray mold infected tomato leaves and captured their hyperspectral images. First images compressed using principal component analysis (PCA) and then sent to KNN, C5.0 and features ranking-KNN (based on selected wavelengths) classifiers. The useful wavelength of the image for FR-KNN was filtered using 5 feature ranking methods namely chernoff bound, kullback-leibler distance, receiver operating characteristic, t-test, and wilcoxon test. The author achieved a disease detection accuracy of $94.83 \%, 96.55 \%$ and $96.55 \%$ with KNN, C5.0, and FR-KNN classifiers respectively. Ali et al. [32] proposed an approach to detect citrus plant diseases, Downy, Anthracnose, Gummosis, Citrus canker, and Citrus greening. Downy and anthracnose infected leaf images were collected from the internet and the remaining captured locally using a DSLR camera. Delta E $(\Delta \mathrm{E})$ algorithm used to segment images by calculating the distance between colors on the leaves. Local binary patterns (LBP) and color histograms (RGB, Hue saturation value (HSV)) used as descriptors. 199 images used for the detection process out of which 99 were disease infected leaves. KNN, SVM, Bagged tree and Boosted tree classifiers used for the disease classification. By providing multiple class tables for training the classifiers, the multilevel classification (Disease level and image level detection) was achieved. Bagged tree ensemble classifier performed better than others and gave an accuracy of $99.5 \%$ (RGB), $100 \%$ (HSV) and 100\% (LBP). Moriya et al. [33] developed a method to identify the Mosaic virus in the sugarcane plantation using an unmanned aerial system (UAS). The SX8 multirotor UAS equipped with a hyperspectral camera (model DT-0014, Rikola), a portable computer (Raspberry Pi), platform positioning inertial navigation system (model IGM-S1, Novatel), an irradiance sensor, and a GPS receiver. To select the most suitable spectral bands, first in-field measurement was performed using spectroradiometer and collected spectral signatures of healthy and virus-infected sugarcane leaves to form a spectral library. The rikola camera configured to capture images according to the spectral bands chosen from the library. The Spectral information divergence process used as the classifier and its classification accuracy estimated with the kappa statistical coefficient and the confusion matrix. The mosaic virus-infected sugarcane area was detected with an accuracy of $92.50 \%$ and got 0.87 kappa coefficient.

Lu et al. [34] used the hyperspectral imaging technique to discriminate tomato leaf disease caused by tomato yellow leaf curl virus. A line scanning spectrograph (Imspector V10E-QE, Spectral Imaging Ltd., Finland), and a CCD camera (C848405G01, Hamamatsu Photonics, Japan) placed in a closed chamber with a $150 \mathrm{~W}$ light source. Hundred infected and sixty-six healthy leaves collected and placed in the chamber to capture hyperspectral images. The captured images processed and analyzed using ENVI 4.6 and Matlab7.14.0 software. From each image sample, eight different features (ASM_MEAN, ENT_MEAN, INE_MEAN, COR_MEAN, ASM_DEV, ENT DEV, INE_DEV, \& COR_DEV) were calculated to transfer image spatial information into numerical values. $853 \mathrm{~nm}$ wavelength was selected to subtract the background from the leaf. $586 \mathrm{~nm}, 720 \mathrm{~nm}$ (two peaks) and $690 \mathrm{~nm}, 840 \mathrm{~nm}$ (two valleys) were chosen as sensitive wavelengths for discriminating infected leaves from healthy ones. The performance of each feature was evaluated by receiver operator characteristic (ROC) curve analysis. Detection accuracy of $100 \%$ was achieved with COR_MEAN texture features based datasets. In 2018, Huang et al. [35] proposed SVM based machine vision technology to detect sugar cane borer disease before planting sugarcane seeds in the field. Sugarcane seeds of $300 \mathrm{~mm}$ images were captured in 3 different angles (with $120^{\circ}$ angle interval) in a sugarcane rotating platform, with those images training and testing datasets were created for SVM classification. Using radial basis function as the kernel function of SVM they achieved 96\% disease detection accuracy. An overview of MVS disease detection methods was shown in Table.2. 
Table 2: Machine vision systems for disease detection

\begin{tabular}{|c|c|c|c|c|c|c|}
\hline Type of Crop & Name of the Disease & Type of Sensor & Spectral bands & Main tool & Accuracy & References \\
\hline Wheat & $\begin{array}{l}\text { Leaf rust } \\
\text { (Puccinia recondita), } \\
\text { Powdery mildew (Blumeria } \\
\text { graminis). }\end{array}$ & $\begin{array}{l}\text { QuickBird Satellite, } \\
\text { Hyperspectral HyMap sensor } \\
\text { a }\end{array}$ & VIS, NIR & $\begin{array}{l}\text { MTMF } \\
\text { (one type of SMA } \\
\text { Algorithm) }\end{array}$ & $88.6 \%$ & {$[20]$} \\
\hline Paddy & $\begin{array}{l}\text { Leaf blast, } \\
\text { Leaf brown spot. }\end{array}$ & $\begin{array}{l}\text { Digital Camera } \\
\text { (Nikon COOLPIX P4) }\end{array}$ & VIS & $\begin{array}{l}\text { SOM Neural } \\
\text { Network }\end{array}$ & $92 \%$ & [21] \\
\hline Sugar beet & $\begin{array}{l}\text { Cercospora beticola, } \\
\text { Uromyces betae. }\end{array}$ & $\begin{array}{l}\text { Digital Camera } \\
\text { (FujiFilm FinePix S5600), } \\
\text { Multispectral Camera } \\
\text { (Tetracam ADC) }\end{array}$ & VIS, NIR & $\begin{array}{l}\text { KNN, Modified } \\
\text { Bayes classifier, } \\
\text { CRF classifier }\end{array}$ & $\begin{array}{c}91 \% \text { (Cercospora } \\
\text { beticola) } 86 \% \text { (Uromyces } \\
\text { betae) }\end{array}$ & [22] \\
\hline Oil palm & Basal stem rot & Quick bird satellite & $\begin{array}{l}\text { Visible, NIR and } \\
\text { Panchromatic }\end{array}$ & GBNDVI & $84 \%$ & {$[25]$} \\
\hline Grape \& & Grape downy mildew, & Digital Camera & VIS & BP Networks & & [26] \\
\hline Wheat & $\begin{array}{l}\text { Grape powdery mildew, } \\
\text { Wheat stripe rust, } \\
\text { Wheat leaf rust. }\end{array}$ & & & Classifier & $100 \%$ & \\
\hline Paddy & $\begin{array}{l}\text { Bacterial blight, } \\
\text { Leaf brown spot, } \\
\text { Rice blast, Sheath rot. }\end{array}$ & Digital Camera & VIS & $\begin{array}{l}\text { Genetic Algorithm, } \\
\text { Rule Generation } \\
\text { Algorithm }\end{array}$ & $94.2 \%$ & [27] \\
\hline Oil palm & $\begin{array}{l}\text { Rice weevils, } \\
\text { Lesser grain borer, } \\
\text { Red flour beetles, } \\
\text { Rusty grain beetles. }\end{array}$ & $\begin{array}{l}\text { FT-IR Spectrometer } \\
\text { (Thermo Fisher } \\
\text { Scientific Inc.) }\end{array}$ & VIS, NIR & $\begin{array}{l}\text { KNN, LDA, NB \& } \\
\text { QDA }\end{array}$ & $\begin{array}{c}>90 \% \\
\text { (LDA Classifier) }\end{array}$ & [28] \\
\hline Citrus & Huanglongbing (HLB) & $\begin{array}{l}\text { Monochrome Camera } \\
\text { (DMK 23G445), } \\
\text { CCD Sensor }\end{array}$ & VIS & SVM & $98.5 \%$ & [29] \\
\hline Bell peppers & $\begin{array}{l}\text { Tomato spotted wilt virus } \\
\text { (TSWV), } \\
\text { Powdery mildew (PM). }\end{array}$ & $\begin{array}{l}\text { VIS Camera and Laser sensor } \\
\text { (DT35, SICK) }\end{array}$ & VIS & $\begin{array}{l}\text { PCA-based } \\
\text { Algorithm, } \\
\text { CV Algorithms }\end{array}$ & $\begin{array}{c}90 \% \text { (PCA-based) } \\
\text { 87\% (one CV algorithm } \\
\text { variant) }\end{array}$ & {$[30]$} \\
\hline Tomato & Gray mold disease. & $\begin{array}{l}\text { Digital CCD Camera } \\
\text { (M C8484-05), } \\
\text { Imaging Spectrograph } \\
\text { (V10E, Specim, Oulu) }\end{array}$ & VIS, NIR & $\begin{array}{l}\text { KNN, C5.0, \& FR- } \\
\text { KKN }\end{array}$ & $\begin{array}{c}94.83 \%(K N N) \\
96.55 \%(\text { C5.0 \& FR-KNN) }\end{array}$ & {$[31]$} \\
\hline Citrus & $\begin{array}{l}\text { Gummosis, } \\
\text { Citrus canker, } \\
\text { Downy, } \\
\text { Citrus greening, } \\
\text { Anthracnose. }\end{array}$ & Digital Camera & VIS & $\begin{array}{l}\mathrm{KNN}, \mathrm{SVM} \text {, Bagged } \\
\text { tree, and Boosted } \\
\text { tree }\end{array}$ & $\begin{array}{l}\text { (Bagged tree ) } \\
99.5 \%(\text { RGB) } \\
100 \%(\mathrm{HSV}) \\
100 \%(\mathrm{LBP})\end{array}$ & [32] \\
\hline Sugarcane & Mosaic virus & $\begin{array}{l}\text { Hyperspectral Camera (model } \\
\text { DT-0014, Rikola), } \\
\text { Spectroradiometer }\end{array}$ & VIS, NIR & $\begin{array}{l}\text { Spectral information } \\
\text { divergence (SID) } \\
\text { Classifier }\end{array}$ & $92.5 \%$ & [33] \\
\hline Tomato & Yellow leaf curl virus. & $\begin{array}{l}\text { Line Scanning Spectrograph } \\
\text { (Imspector V10E-QE), } \\
\text { CCD Camera }\end{array}$ & VIS, NIR & $\mathrm{ROC}$ & $100 \%\left(C O R \_M E A N\right)$ & [34] \\
\hline Sugarcane & Sugar cane borer disease & Digital Camera & VIS & SVM & $96 \%$ & [35] \\
\hline
\end{tabular}

\section{Weed Detection Using Machine Vision}

Plant growing, where it is not wanted is termed as a weed, though no plant is a weed in nature. In crop farming, the yield affecting invasive plants is a serious threat to agriculture. Weeds cause land and water degradation, they host pests, pathogens, and parasites, some create health hazards to humans and animals. Machine vision can keep a watch on the weed presence and its population in the crop. Alchanatis et al. [36]developed an automatic weed detection mechanism in the cotton field with a hyperspectral imaging system comprises a CCD camera (model TM657, Pulnix America Inc.), an acousto-optic tunable filter (TVA100-0.5-1.0., Brimrose Inc.), and a spectral bandpass filter. The output signal of the CCD camera connected to a frame grabber (IVP150, Bar- gold Ltd.) to control image acquisition. The setup was fixed to a tractor which travels along the crop rows to acquire hyperspectral images, for natural sunlight illumination the images were captured between 11:00 to 15:00. Green leaves and bare soil were discriminated by combining 660 and $800 \mathrm{~nm}$ reflectance information. At $660 \mathrm{~nm}$, Rank order algorithms (ROA) used to analyze the segmented hyperspectral images to distinguish between cotton and weed. By observing sharply varying local inhomogeneity exhibited by weeds (local inhomogeneity of cotton plants is low), they achieved a weed detection accuracy of $86 \%$.

Armstrong et al. [37] proposed a method to detect lambs quarters weed at low densities in cornfield using multispectral imaging. They used a three-band CCD multispectral camera that collects image data in the VIS and NIR spectrums. The camera mounted on a GPS enabled airplane captured images from an altitude of $300 \mathrm{~m}$. Crop planted in two different sites (ACRE, TPAC) and data collected from the airplane fed 
into multispectral data analysis software (MultiSpec) which has 4 different algorithms namely spectral angle mapper (SAM), maximum likelihood classifier (MLC), fisher's linear likelihood (LL), minimum Euclidean distance, extraction and classification of homogenous objects (ECHO) spatial-spectral and a matched filter.

MLC gave the highest classification accuracy of $91 \%$ in TPAC and $86 \%$ in ACRE. [38]developed a system to detect broom snakeweed using airborne hyperspectral images and compared them with color-infrared (CIR) photography and digital imagery. A hyperspectral camera (SensiCam), CIR photographic camera (Fairchild Imaging, Milpitas) and three multispectral CIR digital cameras (Kodak MegaPlus) mounted on a twin-engine Cessna 404 aircraft which has taken images at an altitude of $1.68 \mathrm{~km}$ above ground level. Four different classifiers namely minimum distance, Mahalanobis distance, MLC, and SAM used for weed classification. All three types of images analyzed with four different classifiers for detecting the weed. Among all the classifiers, MLC performance is superior and classified weeds in the CIR photographic images with an accuracy of $91 \%, 92 \%$ with CIR digital images, and 95\% with hyperspectral images.

Piron et al. [39] studied a 3D imaging method to detect weeds, matricaria maritima, sonchus asper L., cirsium sp., chenopodium sp., merurialis $\mathrm{m}$. perennis, and brassica sp. in carrot crop using the plant's height as a discriminating parameter. 3D information obtained using the stereoscopic acquisition method based on coded structured light. The stereoscopic device consists of a video projector (OPTOMA EP719, 1024 X 768 resolution) mounted on a movable acquisition device along with the 1.3MP black and white camera (Vector International C-cam BCI 5, Belgium) and a filter wheel. The projector used timemultiplexing pattern projection technique which projects a set of image patterns on the scene (black and white bands of large then finer width). The camera along with filter wheel captures multispectral images of the scene. Fifty-one multispectral images collected from random locations over a period of 19 days with different moisture levels in the field. Plant height was calculated from the images in two stages. In the first stage, QDA was performed to segment plant and ground pixels and in the second stage, both the surfaces joined through soil pixels after alignments final image was created. QDA was used for classification and achieved an accuracy of $83 \%$.

In 2012, de Castro et al. [40]developed a system to detect cruciferous weeds (Diplotaxis spp. and Sinapis spp.) in legumes (pea \& broad bean) and wheat using airborne multispectral imaging. Images captured with a digital DMC Zeiss-Intergraph camera (Green, Red, \& NIR) and a digital CCD camera (RGB) mounted on a turboprop twin-engine plane (CESSNA 404 Titan). Flying at an altitude of $2.5 \mathrm{~km}$, the plane captured the images with a spatial resolution of $250 \mathrm{~cm}$ at a scale of 1:30000 above the field. After radiometric adjustments images were ortho-rectified with ENVI software, then georeferenced. Three different classification methods used, vegetation indices (VI), MLC, and SAM. Among seven locations, at Montalán Alto with MLC, they achieved weed detection accuracy of $99.9 \%$ in pea, $69.8 \%$ in broad bean crops, with VI they got $99.9 \%$ accuracy in pea, $73.7 \%$ in the broad bean with SAM the weed detection accuracy was $98.4 \%$ in pea, $72.7 \%$ in broad bean. At La Carlota, the weed patches in wheat detected with an accuracy of $99.5 \%$ with IV, $98.6 \%$ with MLC and $97.8 \%$ with SAM. Peña et al. [41] developed an early weed detection system in sunflower plantation using the unmanned aerial vehicle (UAV). The images captured by a quadcopter (model md41000, microdrones GmbH, Germany) fitted with a 12MP VIS camera (Olympus PEN E-PMl, Olympus Corporation) and a 1.3MP multispectral camera (Tetracam mini-MCA-6, Tetracam Inc.). Twenty four images captured at a specific pre-programmed altitude with the help of GPS and those images were tagged with corresponding coordinates using the ENVI software (ENVI 4.4, Research Systems Inc.). Tetracam images were pre-processed and aligned with tetracam Pixel wrench 2 software (Tetracam Inc.). UAV captured images with two different cameras, in four different altitudes $(40,60,80 \& 100 \mathrm{~m})$ and in three different days $(44,50 \& 57$ days after sowing (DAS)) to compare weed detection accuracy. Good accuracies achieved with images captured at $40 \mathrm{~m}$ amplitude from 50 DAS crop. The VIS camera detected weed with a maximum accuracy of $77 \%$, where as multispectral camera achieved accuracy of $91 \%$.

Wendel et al. [42] developed a self-supervising hyperspectral autonomous mobile ground vehicle (Ladybird robot) for barnyard grass (Echinochloa crusgalli), curly dock (Rumex Crispus), and caltrop (Tribulus terrestris) weeds detection in the cornfield. The ladybird robot scans two rows of the field at a time mounted with hyperspectral line scanning camera (Resonon Pika II VNIR), and an RGB camera mounted underneath the robot to collect color images of the field. A DSLR camera used to take crop and weed photos for reference, hough transform was used to detect the crop rows. Manually captured weed images with DSLR camera used in training and testing data along with ladybird hyperspectral image data. Both the collected data's pre-processed, normalized and PCA were done to generate test and train data for classification of weed. SVM and LDA classifiers used to generate the classified data. The LDA classifier able to classify robot collected image data quickly compared to SVM. They achieved a detection accuracy of 93\% using LDA and 94\% using SVM with auto-generated data sets. Tamouridou et al. [43] evaluated a method to detect Silybum marianum weed using UAV imagery. A multispectral camera (12MP, Canon S110) mounted on eBee fixed-wing UAV to capture images at an altitude of $115 \mathrm{~m}$. Fifty-five images captured in the field and orthorectified using the Pix4Dmapper Pro software. An ortho-mosaic image was created which comprised red, green and NIR bands and a texture layer based on NIR channel. S. marianum plants spectral signatures taken using UniSpec-DC spectrometer (PP Systems, Inc.) in the field for reference. MLC was used to classify the $\mathrm{S}$. marianum among other weeds and got an overall detection accuracy of $87 \%$ with 1-meter resolution.

López-Granados et al. [44]implemented an airborne system for early detection of pigweed, mustard bindweed, and lambs quarters weeds in the sunflower field. A 12MP digital camera (Olympus PEN E-PMl, Olympus Corporation, Japan) and a 1.3MP multispectral camera (Tetracam mini-MCA-6, 
Tetracam Inc., USA) mounted on a quadcopter UAV (md41000, microdrones GmbH, Germany) for image acquisition. The images acquired from two different sunflower fields at an altitude of $40 \mathrm{~m}$ and $60 \mathrm{~m}$. Captured images from different cameras at different flight altitudes converted to orthomosaic images. Automated and accurate OBIA (Object-based Image Analysis) procedure was developed to detect and map weeds, crop rows, and bare soil. OBIA algorithm detected weeds in the inter-row area of the field and classified its infestation severity based on weed threshold. In both the fields, approximately $100 \%$ weed detection accuracy was achieved using the multispectral camera with a $15 \%$ threshold, and more than $85 \%$ accuracy with 2.5 to $5 \%$ threshold. Digital camera accuracy was $50-60 \%$ at all flight altitudes. Barrero et al. [45] developed a method to identify weeds in the rice field using airborne images. Autonomous delta wind plane (Phantom FX-61) taken aerial images with a 16MP digital CMOS camera (Canon Elph110 HS) at an altitude of $50 \mathrm{~m}$. Mission planner software used for auto control the plane path and auto-capture images. Pix4Dmapper Pro software used for patching captured images to form an orthomosaic map of the entire 5-hectare rice field. Neural networks (NN) used for classification and it was trained with nine descriptors for texture and one for color. They got weed detection accuracy of $99 \%$ using trained NN.

Bakhshipour et al. [46] proposed a system to detect pigweed, lambsquarters, hare's-ear mustard, and turnip weeds in sugar beet crops using texture features. A digital camera took the crop images at a height of $0.5 \mathrm{~m}, 70$ images collected out of which 30 images used for training the algorithm and the remaining 40 for assessment. The Wavelet transform applied to extract the texture features, then the extracted features used in artificial neural networks (ANN) classifier to segment the images. Two manners of classification were studied, discrimination of each plant species against the others and discriminating sugar beet from the weeds, they got the detection accuracy of $96 \%$ with crop-weed distinction approach and $89 \%$ with plant classification approach. Tang et al. [47] implemented cephalanoplos, digitaria, and bindweed weeds detection model in soybean field based on CNN combined with K-means feature learning. Digital camera (Canon EOS 70D, EF-S 18-135mm f/3.5-5.6 IS STM) used for capture images in the field. Traditional CNN uses random initialization of weights but by K-means as pre-training process accuracy of detection was improved. They achieved an accuracy of $92.89 \%$, i.e. $1.82 \%$ additional accuracy compared to ordinary CNN.

Gao et al. [48] proposed a method for the classification of convolvulus arvensis, rumex, and Cirsium arvense weeds in maize (zea mays) fields. They used snapshot mosaic hyperspectral camera to capture 185 spectral features. Random forest model with different spectral features was tested and finally, 30 important spectral features were selected for weed classification. They achieved a precision of $95.9 \%, 70.3 \%$, and 65.9\% for convolvulus arvensis, rumex, and Cirsium arvense weeds respectively. Weed detection methods presented in this paper were outlined in Table.3.

\section{DISCUSSION AND FUTURE DIRECTIONS}

Increased pest attacks, diseases and weed infestations added with climate change, crop yield have been substantially dropped in recent decades. Technological support can help agriculture from its downfall. Many techniques were proposed, developed and implemented in agriculture, machine vision is one among them, which is viable, in the areas like the pests, diseases, and weeds detection, water stress detection, soil nutrients, and post-harvest product quality assessments. The most common pest detection approach is to use an RGB camera that works in the VIS. With the help of traps (sticky solid or fluid trap) and attractants (color, pheromones, light), pests are lured to the place where the camera is placed and the number of pests trapped is used to assess the severity of the damage. This approach can detect them at the early stage of infestation which helps lessen the chemical application and reduces environmental impacts and cost. In VIS sensors, color, patterns and the size of the pest is used for identification and counting. The accuracy of pest detection depends on the type of attractant used (pest dependent), and classification algorithm. Among all, the SVM algorithm is popular. The major challenge in the trap based technique is distinguishing the targeted pests from other trapped insects, pest overlaps, attractant used to entice them, and trap replacement mechanism. Damage symptoms (stress) on the crop also can be used to identify (by using NIR bands along with RGB) the particular pest. Multispectral and hyperspectral imaging use visible and invisible spectral bands to detect crop stress, but premature detection is intractable.

Pathogens like bacteria, viruses, and fungus detection are implausible with traps and lures so direct detection is not feasible with MVS. Their presence in the crop can be assessed by analyzing color and texture changes in the crop. The images are acquired from the field using drones (UAV), satellites and mobile ground robots. For cross verification, ground truth data were collected in case of airborne imaging. Generally used classifiers include MLC, KNN, SVM, and PCA. In the case of weeds, detection is possible in the early stage of crop growth as later crop weed overlap may create difficulties in detection, such cases must be addressed by the researchers. Colour, shape and texture features are used for discriminating weed from the crop. MVS disease and weed identification techniques prefer multispectral and hyperspectral imaging since they capture crop reflections better than VIS.

The developed systems are studied in ideal conditions which in the real world may have complications. Satellite imaging can detect pests, diseases, and weed infestations on a larger scale with less complexity, but the frequency of data updates and cost to retrieve them is a bottleneck. The major challenges with drones are the reliability issues and accuracy of the mosaic image. Now they are coming with sophisticated software for auto flight and automatic image stitching of the whole field and reasonably low cost which will in the near future help new researchers explore more drone-based MVS methods in agriculture.

The spectral response of the remote sensing data can be affected by variable soil backgrounds and residue covers, which will 
Table 3: Machine vision systems for weed detection

\begin{tabular}{|c|c|c|c|c|c|c|}
\hline Type of Crop & Name of the Weed & Type of Sensor & Spectral bands & Main tool & Accuracy & References \\
\hline Cotton & General & $\begin{array}{l}\text { CCD Camera } \\
\text { (Model TM657, Pulnix America Inc.) } \\
\text { with NIR filter removed }\end{array}$ & VIS, NIR & $\begin{array}{l}\text { Rank Order } \\
\text { Algorithms }\end{array}$ & $86 \%$ & [36] \\
\hline Corn \& & Lambs quarters & CCD Multispectral & VIS, NIR & MLC & $91 \%$ (in TPAC) & {$[37]$} \\
\hline Soybean & & Camera & & & $86 \%($ in $A C R E)$ & \\
\hline Multiple Crops & Broom snakeweed & $\begin{array}{l}\text { Hyperspectral Camera (SensiCam), } \\
\text { Multispectral Camera } \\
\text { (Kodak MegaPlus), \& } \\
\text { CIR Photographic Camera (Fairchild } \\
\text { Imaging) }\end{array}$ & VIS, NIR & $\begin{array}{l}\text { Minimum } \\
\text { distance, } \\
\text { Mahalanobis } \\
\text { distance, } \\
\text { MLC \& SAM }\end{array}$ & $\begin{array}{l}91 \% \text { (CIR photographic), } \\
92 \% \text { (CIR digital image), } \\
\text { 95\% (Hyperspectral). }\end{array}$ & {$[38]$} \\
\hline Carrot & $\begin{array}{l}\text { Matricaria maritime, } \\
\text { Sonchus asper L., } \\
\text { Cirsium sp., } \\
\text { Chenopodium sp., } \\
\text { Merurialis M. perennis, } \\
\text { Brassica sp.. }\end{array}$ & $\begin{array}{l}\text { Video projector (OPTOMA EP719), } \\
\text { 1.3MP black and white Camera }\end{array}$ & VIS & QDA & $83 \%$ & [39] \\
\hline $\begin{array}{l}\text { Pea, } \\
\text { Broad-bean \& } \\
\text { Wheat }\end{array}$ & $\begin{array}{l}\text { Diplotaxis spp., } \\
\text { Sinapis spp.. }\end{array}$ & $\begin{array}{l}\text { Digital CCD Camera, DMC Zeiss- } \\
\text { Intergraph Camera }\end{array}$ & $R, G, N I R$ & $\begin{array}{l}\text { MLC, VI, } \\
\text { and SAM }\end{array}$ & $\begin{array}{c}99.9 \% \text { (M LC\&VI in pea) } \\
73.7 \% \text { (VI in broad bean) } \\
99.5 \% \text { (VI in wheat) }\end{array}$ & [40] \\
\hline Sunflower & General & $\begin{array}{l}\text { Digital Camera (Olympus PEN E-PM1), } \\
\text { 1.3MP Multispectral Camera (Tetracam } \\
\text { mini-MCA-6) }\end{array}$ & VIS, NIR & $\begin{array}{l}\text { Spectral } \\
\text { Information } \\
\text { Divergence } \\
\text { Classifier }\end{array}$ & $\begin{array}{l}\text { 77\% (with digital cam) } \\
91 \% \text { (with Tetracam) }\end{array}$ & {$[41]$} \\
\hline Corn & $\begin{array}{l}\text { Barnyard grass, } \\
\text { Curly dock, } \\
\text { Ipomoea spp., } \\
\text { Polymeria spp., } \\
\text { Caltrop. }\end{array}$ & $\begin{array}{l}\text { Hyperspectral Camera (Resonon Pika } \\
\text { II VNIR), } \\
\text { RGB Camera, \& DSLR Camera }\end{array}$ & VIS, NIR & $\begin{array}{l}\text { SVM and } \\
\text { LDA }\end{array}$ & $\begin{array}{l}93 \%(\text { LDA }) \\
94 \%(\text { SVM })\end{array}$ & [42] \\
\hline $\begin{array}{l}\text { Multiple } \\
\text { Crops }\end{array}$ & Silybum marianum & $\begin{array}{l}\text { Multispectral Camera } \\
\text { (12MP, Canon S110 NIR ) }\end{array}$ & $R, G, N I R$ & MLC & $87 \%$ & [43] \\
\hline Sunflower & $\begin{array}{l}\text { Pigweed, } \\
\text { Mustard, } \\
\text { Bindweed, } \\
\text { Lambsquarters. }\end{array}$ & $\begin{array}{l}\text { 12MP Digital Camera (Olympus PEN } \\
\text { E-PM 1), } \\
\text { 1.3MP Multispectral Camera }\end{array}$ & VIS, NIR & OBIA & $\begin{array}{l}100 \% \text { (with } 15 \% \text { weed } \\
\text { threshold) } \\
>85 \% \text { (with } 2.5-5 \% \\
\text { threshold) }\end{array}$ & {$[44]$} \\
\hline Paddy & General & Digital Camera & VIS & $\begin{array}{l}\text { Neural } \\
\text { Networks }\end{array}$ & $99 \%$ & {$[45]$} \\
\hline Sugar beet & $\begin{array}{l}\text { Pigweed, } \\
\text { Lambsquarters, } \\
\text { Hare's-ear mustard, } \\
\text { Turnip weed. }\end{array}$ & Digital Camera & VIS & ANN & $\begin{array}{l}96 \% \text { (Crop-weed } \\
\text { distinction) } \\
89 \% \text { (Plant } \\
\text { classification) }\end{array}$ & [46] \\
\hline Soybean & $\begin{array}{l}\text { Cephalanoplos, } \\
\text { Digitaria, } \\
\text { Bindweed. }\end{array}$ & $\begin{array}{l}\text { Digital Camera } \\
\text { (Canon EOS 70D, EF-S } \\
\text { 18-135mm f/3.5-5.6 IS STM) }\end{array}$ & VIS & CNN & $92.89 \%$ & [47] \\
\hline Maize & $\begin{array}{l}\text { Convolvulus arvensis, } \\
\text { Rumex, } \\
\text { Cirsium arvense. }\end{array}$ & Snapshot Mosaic Hyperspectral Camera & VIS, NIR & $\begin{array}{l}\text { Random } \\
\text { Forest }\end{array}$ & $\begin{array}{c}95.9 \% \text { (convolvulus } \\
\text { arvensis),70.3\% (Rumex) } \\
\text { and } 65.9 \% \text { (cirsium } \\
\text { arvense) }\end{array}$ & [48] \\
\hline
\end{tabular}

affect the detection accuracy so more attention must be given on this issue. Control measures must be taken before damage crosses the action threshold to avoid economic loss. Widespread commercialization of MVS in agriculture is possible only with robust, low cost, automated unified detection systems (pest, weed, and diseases). The future research focus must be on MVS capable of detecting all yield affecting factors of a particular crop. Multi-crop detection variant is preferable since farmers use the same field for different crops in different seasons in a year. Internet of Things technology [49] must be exploited in agriculture for the real-time automatic pest detection system. The system cost can be reduced by using low cost programmable hardware's (Arduino, Raspberry Pi, Intel's Edition, Beagle bone and so forth) with open software, connected to cloud servers (Amazon web services, Microsoft Azure, Google Cloud and others) for processing the image information to detect stress and alerting the farmer to take action at a particular geo-location. In the future before the farmer gets up, every morning UAV's fitted with sophisticated cameras will take off and locate whether there are any crop health issues within the field.

\section{CONCLUSION}

In this review paper, various machine vision techniques proposed for classification and detection of pests, disease, and weeds in the agriculture field were presented and their key points were tabulated. In the near future, agriculture needs to become more like manufacturing factories to continue to feed the world. Increasing the efficiency of crop production is very important and is possible with technological support. In agriculture, MVS 
is a likely option in dealing with pests, diseases, and weeds which can save about $30 \%$ of the crop yield. Machine vision systems linked with fungicide, pesticide, and herbicide sprayers autonomously monitoring crop health and taking suitable action against the crop-damaging factors will be a regular operation in the future. There are still many notable deficiencies related to the image sensor's ability, platform dependability, and lack of standardized procedure. With the advancements in image processing methods, low-cost hardware and more research focus in this domain there will be a greater benefit of these systems in precision agriculture.

\section{REFERENCES}

1. S. Melorose, J., Perroy, R., \& Careas, "World population prospects," United Nations, vol. 1, no. 6042, pp. 587-92, 2015.

2. Oerke, E-C. "Crop losses to pests." The Journal of Agricultural Science, vol.144, no. 1, pp. 31-43, 2006

3. Y. Chen, K. Chao, and M. S. Kim, "Machine vision technology for agricultural applications," Comput. Electron. Agric., vol. 36, pp. 173-191, 2002.

4. Robert A. Schowengerdt, Techniques for image processing and classifications in remote sensing, Academic Press. 2012.

5. J. Huang, W., Lamb, D. W., Niu, Z., Zhang, Y., Liu, L., \& Wang, "Identification of yellow rust in wheat using in-situ spectral reflectance measurements and airborne hyperspectral imaging," Precis. Agric., vol. 8, no. 4-5, pp. 187-197, 2007.

6. N. D. G. Singh, C. B., Jayas, D. S., Paliwal, J., \& White, "Detection of insect-damaged wheat kernels using near-infrared hyperspectral imaging," J. Stored Prod. Res., vol. 45, no. 3, pp. 151-158, 2009.

7. N. D. Singh, C. B., Jayas, D. S., Paliwal, J., \& White, "Identification of insect-damaged wheat kernels using short-wave near-infrared hyperspectral and digital colour imaging," Comput. Electron. Agric., vol. 73, no. 2, pp. 118-125, 2010.

8. Q. Yao et al., "An Insect Imaging System to Automate Rice Light-Trap Pest Identification," J. Integr. Agric., vol. 11, no. 6, pp. 978-985, 2012.

9. Q. Yao et al., "Segmentation of touching insects based on optical flow and NCuts," Biosyst. Eng., vol. 114, no. 2, pp. 67-77, 2013.

10. M. J. Asefpour Vakilian K, "Performance evaluation of a machine vision system for insect pests identification of field crops using artificial neural networks," Arch. Phytopathol. plant Prot., vol. 46, no. 11, pp. 1262-1269, 2013.

11. T. A. N. G. Qing, Y., Xian, D. X., Liu, O. J., Yang, B. J., Diao, G. Q., \& Jian, "Automated counting of rice planthoppers in paddy fields based on image processing," J. Integr. Agric., vol. 13, no. 8, pp. 1736-1745, 2014.

12. R. N. Prasannakumar, N. R., Chander, S., \& Sahoo, “Characterization of brown planthopper damage on rice crops through hyperspectral remote sensing under field conditions," Phytoparasitica, vol. 42, no. 3, pp. 387-395, 2014.

13. W. Ding and G. Taylor, "Automatic moth detection from trap images for pest management," Comput. Electron. Agric., vol. 123, pp. 17-28, 2016.

14. L. P. Rajan, P., Radhakrishnan, B., \& Suresh, "Detection and classification of pests from crop images using Support Vector Machine," 2016 Int. Conf. Emerg. Technol. trends (ICETT).IEEE, pp. 1-6, 2016.

15. A. E. Doitsidis, L., Fouskitakis, G. N., Varikou, K. N., Rigakis, I. I., Chatzichristofis, S. A., Papafilippaki, A. K., \& Birouraki, "Remote monitoring of the Bactrocera oleae (Gmelin)(Diptera: Tephritidae) population using an automated McPhail trap," Comput. Electron. Agric., vol. 137, pp. 69-78, 2017.

16. M. A. Ebrahimi, M. H. Khoshtaghaza, S. Minaei, and B. Jamshidi, "Vision-based pest detection based on SVM classification method," Comput. Electron. Agric., vol. 137, pp. 52-58, 2017.

17. Z. Sun, Y., Liu, X., Yuan, M., Ren, L., Wang, J., \& Chen, "Automatic in-trap pest detection using deep learning for pheromone-based Dendroctonus valens monitoring," Biosyst. Eng., vol. 176, pp. 140-150, 2018.

18. V. Partel, L. Nunes, P. Stansly, and Y. Ampatzidis, "Automated visionbased system for monitoring Asian citrus psyllid in orchards utilizing artificial intelligence," Comput. Electron. Agric., vol. 162, no. April, pp. 328-336, 2019.

19. A. B. Yialouris, C. P., \& Sideridis, "An expert system for tomato diseases," Comput. Electron. Agric., vol. 14, no. 1, pp. 61-76, 1996.

20. G. Franke, J., \& Menz, "Multi-temporal wheat disease detection by multi-spectral remote sensing," Precis. Agric., vol. 8, no. 3, pp. 161-172, 2007.

21. J. Phadikar, S., \& Sil, "Rice disease identification using pattern recognition techniques," 2008 11th Int. Conf. Comput. Inf. Technol. IEEE, pp. 420-423, 2008.

22. W. Bauer, S. D., Korč, F., \& Förstner, "The potential of automatic methods of classification to identify leaf diseases from multispectral images," Precis. Agric., vol. 12, no. 3, pp. 361-377, 2011.

23. W. Läbe, T., \& Förstner, "Automatic relative orientation of images," Proc. 5th Turkish-German Jt. Geod. Days, vol. 29, no. 31, 2006.

24. C. Lemaire, "Aspects of the DSM production with high resolution images," Int. Arch. Photogramm. Remote Sens. Spat. Inf. Sci., vol. 37, no. B4, pp. 1143-1146, 2005.

25. B. Santoso, H., Gunawan, T., Jatmiko, R. H., Darmosarkoro, W., \& Minasny, "Mapping and identifying basal stem rot disease in oil palms in North Sumatra with QuickBird imagery," Precis. Agric., vol. 12, no. 2, pp. 233-248, 2011.

26. X. Wang, H., Li, G., Ma, Z., \& Li, "Image recognition of plant diseases based on backpropagation networks," 2012 5th Int. Congr. Image Signal Process., pp. 894-900, 2012.

27. S. Phadikar, J. Sil, and A. K. Das, "Rice diseases classification using feature selection and rule generation techniques," Comput. Electron. Agric., vol. 90, pp. 76-85, 2013

28. S. Liaghat, S., Mansor, S., Ehsani, R., Shafri, H. Z. M., Meon, S., \& Sankaran, "Mid-infrared spectroscopy for early detection of basal stem rot disease in oil palm," Comput. Electron. Agric., vol. 101, pp. 48-54, 2014.

29. E. Pourreza, A., Lee, W. S., Ehsani, R., Schueller, J. K., \& Raveh, “An optimum method for real-time in-field detection of Huanglongbing disease using a vision sensor," Comput. Electron. Agric., vol. 110, no. 1, pp. 221-232, 2015.

30. S. Schor, N., Bechar, A., Ignat, T., Dombrovsky, A., Elad, Y., \& Berman, "Robotic disease detection in greenhouses: combined detection of powdery mildew and tomato spotted wilt virus," IEEE Robot. Autom. Lett., vol. 1, no. 1, pp. 354-360, 2016.

31. C. Xie, C. Yang, and Y. He, "Hyperspectral imaging for classification of healthy and gray mold diseased tomato leaves with different infection severities," Comput. Electron. Agric., vol. 135, pp. 154-162, 2017.

32. B. A. Ali, H., Lali, M. I., Nawaz, M. Z., Sharif, M., \& Saleem, “Symptom based automated detection of citrus diseases using color histogram and textural descriptors," Comput. Electron. Agric., vol. 138, pp. 92-104, 2017.

33. G. T. Moriya, E. A. S., Imai, N. N., Tommaselli, A. M. G., \& Miyoshi, "Mapping mosaic virus in sugarcane based on hyperspectral images," IEEE J. Sel. Top. Appl. Earth Obs. Remote Sens., vol. 10, no. 2, pp. 740-748, 2016.

34. H. Lu, J., Zhou, M., Gao, Y., \& Jiang, "Using hyperspectral imaging to discriminate yellow leaf curl disease in tomato leaves," Precis. Agric., vol. 19, no. 3, pp. 379-394, 2018.

35. T. Huang, R. Yang, W. Huang, Y. Huang, and X. Qiao, "Detecting sugarcane borer diseases using support vector machine," Inf. Process. Agric., vol. 5, no. 1, pp. 74-82, 2018.

36. L. Alchanatis, V., Ridel, L., Hetzroni, A., \& Yaroslavsky, "Weed detection in multi-spectral images of cotton fields," Comput. Electron. Agric. vol. 47, no. 3, pp. 243-260, 2005.

37. K. D. Armstrong, J. J. Q., Dirks, R. D., \& Gibson, "The use of early season multispectral images for weed detection in corn," Weed Technol., vol. 21, no. 4, pp. 857-862, 2007

38. J. H. Yang, C., \& Everitt, "Comparison of hyperspectral imagery with aerial photography and multispectral imagery for mapping broom snakeweed," Int. J. Remote Sens., vol. 31, no. 20, pp. 5423-5438, 2010.

39. M. F. Piron, A., van der Heijden, F., \& Destain, "Weed detection in 3D images," Precis. Agric., vol. 12, no. 5, pp. 607-622, 2011.

40. F. de Castro, A. I., Jurado-Expósito, M., Peña-Barragán, J. M., \& LópezGranados, "Airborne multi-spectral imagery for mapping cruciferous weeds in cereal and legume crops," Precis. Agric., vol. 13, no. 3, pp. 302-321, 2012.

41. F. Peña, J., Torres-Sánchez, J., Serrano-Pérez, A., de Castro, A., \& López-Granados, "Quantifying efficacy and limits of unmanned aerial 
vehicle (UAV) technology for weed seedling detection as affected by sensor resolution," Sensors, vol. 15, no. 3, pp. 5609-5626, 2015.

42. J. Wendel, A., \& Underwood, "Self-supervised weed detection in vegetable crops using ground based hyperspectral imaging," 2016 IEEE Int. Conf. Robot. Autom. (ICRA). IEEE, pp. 5128-5135, 2016.

43. D. Tamouridou, A. A., Alexandridis, T. K., Pantazi, X. E., Lagopodi, A. L., Kashefi, J., \& Moshou, "Evaluation of UAV imagery for mapping Silybum marianum weed patches," Int. J. Remote Sens., vol. 38, no. 8-10, pp. 2246-2259, 2017.

44. J. M. López-Granados, F., Torres-Sánchez, J., Serrano-Pérez, A., de Castro, A. I., Mesas-Carrascosa, F. J., \& Pena, "Early season weed mapping in sunflower using UAV technology : variability of herbicide treatment maps against weed thresholds," Precis. Agric., vol. 17, no. 2, pp. 183-199, 2016.

45. S. Barrero, O., Rojas, D., Gonzalez, C., \& Perdomo, "Weed Detection in Rice Fields Using Aerial Images and Neural Networks," 2016 XXI
Symp. Signal Process. Images Artif. Vis. (STSIVA).IEEE, pp. 1-4, 2016

46. D. Bakhshipour, A., Jafari, A., Nassiri, S. M., \& Zare, "Weed segmentation using texture features extracted from wavelet subimages," Biosyst. Eng., vol. 157, pp. 1-12, 2017.

47. J. Tang, D. Wang, Z. Zhang, L. He, J. Xin, and Y. Xu, "Weed identification based on K-means feature learning combined with convolutional neural network cephalanoplos digitaria bindweed soybean," Comput. Electron. Agric., vol. 135, pp. 63-70, 2017.

48. J. G. Gao, J., Nuyttens, D., Lootens, P., He, Y., \& Pieters, "Recognising weeds in a maize crop using a random forest machine-learning algorithm and near-infrared snapshot mosaic hyperspectral imagery," Biosyst. Eng., vol. 170, pp. 39-50, 2018.

49. C. Tzounis, A., Katsoulas, N., Bartzanas, T., \& Kittas, "Internet of Things in agriculture, recent advances and future challenges," Biosyst. Eng. vol. 164, pp. 31-48, 2017. 